\title{
A felicidade da população trabalhadora de Cascavel/PR segundo a métrica do índice de Felicidade Interna Bruta
}

\author{
Happiness of Cascavel-PR working population according to the Gross Domestic \\ Happiness index
}

Tatiani Sobrinho Del Bianco, Edicléia Lopes Da Cruz Souza, Nadja Simone Menezes Nery De Oliveira, Pery Francisco Assis Shikida

Universidade Estadual do Oeste do Paraná (UNIOESTE), Toledo, PR, Brasil

\section{Resumo}

O presente estudo objetiva identificar quais as variáveis que mais influenciam na felicidade dos trabalhadores do município de Cascavel, no Estado do Paraná. Para tanto, aplicou-se a estatística descritiva sobre dados coletados a partir da aplicação de um questionário, elaborado com base na metodologia adaptada do índice de Felicidade Interna Bruta (FIB). Dentre os questionamentos, os indivíduos foram perguntados: sobre a frequência com que praticavam atividade física; se tinham boas noites de sono, tranquilo e profundo; quanto ao uso do tempo, que é um dos mais significativos fatores na qualidade de vida, especialmente para lazer e socialização com família e amigos. A gestão equilibrada do tempo foi avaliada incluindo tempo no trânsito, no trabalho, nas atividades educacionais, no lazer etc. Dos resultados, ser otimista, praticar exercícios físicos e participar de algum grupo social foram fatores que afetavam positivamente a felicidade dos indivíduos. E, ainda, como resposta à pergunta sobre o que os deixavam mais felizes, identificou-se a preferência por fatores não materiais, despontando especialmente aqueles associados à família, aos bons sentimentos, às boas práticas em sociedade, à saúde, à solidariedade e à espiritualidade.

Palavras-chave: Felicidade. FIB. População trabalhadora. Market behaviour. Cascavel/PR.

\section{Abstract}

This study aims to identify which variables most influence the workers happiness in the city of Cascavel, PR. Therefore, it applied the descriptive statistics on data collected from a questionnaire elaborated based on the adapted methodology of Gross National Happiness index-FIB. Among the questions the individuals were asked

TSB é economista, doutoranda do Programa de Pós-graduação em Desenvolvimento Regional e Agronegócio, e-mail: tatiani.sdelbianco@gmail.com

ELCS é economista, doutoranda do Programa de Pós-graduação em Desenvolvimento Regional e Agronegócio, e-mail: edicleia.souza@unioeste.br

NSMNO é economista, doutoranda do Programa de Pós-graduação em Desenvolvimento Regional e Agronegócio, e-mail: nadja_menezes@hotmail.com

PFAS é professor doutor associado do Curso de Economia do Programa de Pós-Graduação em Economia e do Programa de Mestrado e Doutorado em Desenvolvimento Regional e Agronegócio da Universidade Estadual do Oeste do Paraná (Unioeste), e-mail: peryshikida@hotmail.com 
on how often they practice physical activity; had good a night of quiet and deep sleep; about the use of time, considering that this is one of the most significant factors in the quality of life, especially the time for leisure and socializing with family and friends. Balanced time management was assessed, including time in traffic, at work, in educational activities, leisure, etc. Among the results, being optimistic, the practice of physical exercises, participation in a social group, are factors that positively affect the happiness of individuals. And yet, in response to the question on what make them happier, we identified the preference for non-material factors, especially those related to family, good feelings, good practices in society, health, solidarity and spirituality.

Keywords: Happiness. FIB. Working population. Market behaviour. Cascavel-PR.

\section{Introdução}

A felicidade é algo de difícil mensuração, uma vez que difere em grau, estágio e fontes para cada indivíduo. Nas últimas décadas, a tentativa de compreendê-la tem gerado discussões por estudiosos de diferentes áreas, dentre as quais está a economia. Os estudos nessa área vêm ganhando notoriedade desde os anos de 2000, demonstrando como a temática é passível de análise alternativa, além de esforços para a criação de indicadores capazes de captar e de indicar o fenômeno. No campo acadêmico da economia e da felicidade, há uma linha de estudo denominada de comportamento de mercado (market behaviour), que apresenta uma leitura de trabalhos que enfocam a relação de aspectos econômicos com a felicidade. Nessa temática, o número de pesquisadores que tentam medir quanto vale a felicidade, no sentido de sua relação com a economia, vem aumentando nos últimos anos (Rodrigues \& Shikida, 2005).

Na busca de respostas e de métricas explicativas, pesquisas, em meados de 1947, criaram o indicador do Produto Interno Bruto (PIB), que disseminou mundialmente o uso de indicadores, basicamente econômicos, para medir o progresso da economia de um país. A partir da década de 1960, surgiu nos Estados Unidos um indicador que visava deslocar o foco de aspectos econômicos para contemplar parâmetros que pudessem aferir o bem-estar da população - os indicadores sociais (Sales et al., 2013).

Segundo Louette (2007), a proposta de novos indicadores destina-se a criar uma base estatística para medir os resultados das políticas sociais, ambientais e de desenvolvimento econômico. Dessa forma, a Organização de Cooperação e de Desenvolvimento Econômico (OCDE), com o apoio do Banco da Itália e do Centro de Pesquisa da Comissão Europeia (CCI), reuniu, em Roma, especialistas sobre o tema "Podemos medir a felicidade? 0 que estas medidas significam para a ação pública?" para verificar em que medida o bem-estar poderia afetar os modelos econômicos e a ação governamental. A felicidade não é um sentimento novo, no entanto continua difícil de ser medido. Esse foi também um dos objetivos atribuídos pela OCDE no âmbito do fórum mundial, em Istambul, na Turquia, em junho de 2007.

Nesse contexto, com o apoio do Programa das Nações Unidas para o Desenvolvimento (PNUD), foi criado, em 1972, no Reino do Butão, o índice de Felicidade Interna Bruta (FIB). Nesse conceito, o cálculo da "riqueza" deve considerar outros aspectos além do crescimento econômico, como a conservação do meio ambiente e a qualidade de vida das pessoas. 0 índice FIB baseia-se na premissa de que o objetivo principal de uma sociedade deve ser a integração do desenvolvimento material com o psicológico, o cultural e o espiritual. Para tanto, o cálculo desse indicador engloba nove dimensões: bem-estar psicológico, saúde, uso do tempo, vitalidade comunitária, educação, cultura, meio ambiente, padrão de vida e governança (FIB, 2015).

No Brasil, as primeiras iniciativas para implantação desse índice de desenvolvimento foram realizadas pelo Instituto Visão Futuro. A versão brasileira do índice foi aplicada em projetos-piloto no Estado de São Paulo (cidades de Angatuba e de Itapetininga). De acordo com pesquisadores brasileiros, o FIB não é meramente um indicador, mas também um catalisador de mudança, um processo de mobilização social em prol da coletividade e do desenvolvimento sustentável, visando ao bem-estar de todos (Sales et al., 2013; Visão do Futuro, 2015).

A partir do Relatório Mundial da Felicidade elaborado por Helliwell et al. (2013), correlacionou-se 
a classificação de algumas das maiores economias do mundo aos países mais felizes. 0 que se pode perceber é que nem sempre as economias que se despontam em termos econômicos se confirmam da mesma forma no quesito felicidade. Por exemplo, os Estados Unidos são a primeira economia do mundo, mas o 17ํㅜ país mais feliz. Os países nórdicos, Dinamarca, Noruega, Suíça, Holanda e Suécia, foram classificados como os cinco países mais felizes do mundo, no entanto não lideram a lista das primeiras economias. 0 Brasil, por sua vez, ocupa a 24⿳亠丷厂 posição do FIB e foi considerado pelo Banco Mundial, em 2011, a sétima maior economia mundial (Banco Mundial, 2011).

Diante desses dados, nota-se que o crescimento econômico dos países não está proporcionalmente atrelado ao grau de bem-estar da sua população. Dessa constatação surgiu a diretriz para esta pesquisa, cujo objetivo visa identificar a contribuição das variáveis sociais, econômicas, de bem-estar e ambientais para o nível de felicidade da população de um caso especifico, ou seja, de Cascavel, no Estado do Paraná. A delimitação espacial para o estudo se deu em função de que esse município é o quinto mais populoso e também por despontar em termos econômicos no tocante à mesorregião Oeste Paranaense, onde se localiza. Ainda, apresenta-se com expressivo grau de urbanização (94,3\% em 2010) e demonstra contínua capacidade de crescimento econômico.

De acordo com o Instituto Paranaense de Desenvolvimento Econômico e Social (IPARDES, 2015), o município está entre as cidades paranaenses com taxa de pobreza inferior a $30 \%$ da população, com um Índice de Desenvolvimento Humano Municipal (IDH-M) de 0,782 e Índice de Gini de 0,5206. A geração de emprego tem se expandido, ocupando cerca de 95\% da população economicamente ativa, em 2010. Além disso, a disponibilidade de um aparato de entidades voltadas à ciência, tecnologia e inovação, e uma estrutura universitária atuante e em expansão, tanto em Cascavel quanto na mesorregião Oeste Paranaense, são elementos essenciais que podem ser articulados visando à promoção da inclusão social e do desenvolvimento regional, cujo foco é a ampliação do bem-estar da população.

Todos esses elementos citados, conjuntamente, sugerem que a população de Cascavel apresenta fatores que a predispõem a sentir-se feliz. Verificar quais as variáveis que mais influenciam nesse processo é o que se propõe nesta discussão. Para tanto, realizou-se levantamento de dados da população trabalhadora cascavelense a partir da aplicação de questionário elaborado com base nos pressupostos do FIB para a felicidade.

0 artigo contém cinco seções, incluindo esta introdução. Na seção 2, apresentam-se a conceituação história e uma breve revisão da literatura sobre o FIB. Em seguida expõem-se, na seção 3, os procedimentos metodológicos adotados, bem como as bases dos dados coletados. A seção 4 contempla a análise resultante da estatística descritiva dos dados obtidos na pesquisa de campo. As conclusões acerca do tema sumarizam este trabalho.

\section{O indicador Felicidade Interna Bruta (FIB): conceituação e discussão}

As discussões sobre o desenvolvimento econômico a partir da primeira metade do século XX têm colocado em xeque os fatores que o promovem e como a população tem sido incluída nesse processo. No cerne dessa discussão está o fato de que os aspectos sociais, ambientais e culturais devem ser somados ao crescimento da riqueza para análise do desenvolvimento de uma sociedade. Nesse contexto, foi elaborado pelo rei Jigme Singya Wangchuck, em 1972, do Reino do Butão, o indicador FIB, cuja ideia é mostrar que o objetivo maior de uma sociedade não deve concentrar-se no crescimento econômico, mas na integração de todos os aspectos da vida dos indivíduos, o que inclui o material, o psicológico, o cultural e o espiritual (FIB, 2015). Tais fatores determinam a qualidade de vida dos indivíduos e o quanto se sentem satisfeitos, influenciando a sua felicidade. Desde a concepção do FIB, o PNUD tem apoiado a aplicação prática desse conceito em projetos em diversos países, inclusive no Brasil. De acordo com Helliwell et al. (2013), caso queira inferir os níveis de felicidade e de miséria, primeiro devem-se saber os motivos que lhes causam.

Pensando individualmente, cada pessoa tem sua própria composição genética, que, ao interagir com o ambiente em que vive, determina as suas principais características, seja externa ou pessoal. Dos fatores externos, os principais determinantes da felicidade são: renda, trabalho, comunidade, governo, valores 
e religião. Dentre as características pessoais, os determinantes-chave incluem: saúde mental, saúde física, experiência familiar, educação, sexo e idade. Logo, o indicador da felicidade é formado por nove dimensões, conforme resume o Quadro 1, visando englobar todas essas características.

Ressalta-se que, no geral, as dimensões estabelecidas pelo FIB podem ser consideradas consistentes com a realidade das diferentes regiões, uma vez que os fatores que contribuem para a felicidade das pessoas são semelhantes, mesmo tratando-se de culturas diversas. $\mathrm{O}$ que pode ocorrer é que, conforme a cultura, dá-se mais ou menos ênfase em algum dos indicadores, porém eles são universalmente comuns.

Considerando os aspectos citados, o mapa da felicidade mundial, publicado por Roncolato (2013), apresenta a Dinamarca, Noruega, Suíça, Holanda e Suécia como os países mais felizes, enquanto que o Brasil está na 24ㅁa posição, seguido por França, Alemanha, Qatar, Chile e Argentina, países que foram classificados com grau de felicidade intermediário. Já os países de Togo, Benin e República Centro-Africana, todos na África Subsaariana, ocuparam as últimas colocações. Destaca-se ainda a atuação dos Estados Unidos, que, figurados como a primeira potência mundial, ficaram classificados em $17^{\circ}$ lugar no quesito felicidade, logo atrás do México. De acordo ainda com a publicação, o bem-estar é um componente importante na medida do desenvolvimento econômico e social do planeta, por isso cada vez mais os líderes mundiais estão considerando-o como um guia para seus países e o mundo.

O bem-estar social, entretanto, não é tema de debate só para os gestores públicos. Várias pesquisas acadêmicas vêm sendo desenvolvidas na busca de compreender a satisfação dos indivíduos. Tais estudos cresceram paulatinamente nas últimas décadas, isso porque, em um mundo em que o capital e a tecnologia predominam, a disponibilidade e o acesso a bens e serviços têm influenciado no modo e na condição de vida das pessoas, no seu bem-estar e, consequentemente, na sua felicidade. Daí a necessidade de se estudar e compreender o que tem feito as pessoas se sentirem felizes.

No intuito de quantificar as pesquisas existentes sobre o tema felicidade, fez-se uma varredura nos

Quadro 1 - Composição do indicador de Felicidade Interna Bruta (FIB)

\begin{tabular}{|c|c|c|}
\hline Dimensões & Componentes & Objetivo \\
\hline $\mathbf{i}$ & Bem-estar psicológico & $\begin{array}{l}\text { Avaliar o grau de satisfação e de otimismo de cada indivíduo em relação à sua própria vida. Os indicadores incluem a } \\
\text { prevalência de taxas de emoções positivas e negativas, e analisam a autoestima, a sensação de competência, o estresse e as } \\
\text { atividades espirituais. }\end{array}$ \\
\hline ii & Saúde & $\begin{array}{l}\text { Medir a eficácia das políitcas de saúde com critérios como autoavaliaç̃ão da saúde, invalidez, padrões de comportamento } \\
\text { arriscados, exercício, sono, nutrição etc. }\end{array}$ \\
\hline iii & Uso do tempo & $\begin{array}{l}0 \text { uso do tempo é um dos mais significativos fatores na qualidade de vida, especialmente para lazer e socializaccão com família } \\
\text { e amigos. A gestão equilibrada do tempo é avaliada incluindo tempo no trânsito, no trabalho, nas atividades educacionais etc. }\end{array}$ \\
\hline iv & Vitalidade comunitária & $\begin{array}{l}\text { Focar nos relacionamentos e interaç̃eses nas comunidades. Examinar o nível de confiança, a sensaç̃ão de pertencimento, a } \\
\text { vitalidade dos relacionamentos afetivos, a segurança em casa e na comunidade, a prática de doação e de voluntariado. }\end{array}$ \\
\hline $\mathbf{v}$ & Educação & $\begin{array}{l}\text { Levar em consideração fatores como participação em educação formal e informal, competências, envolvimento na educação } \\
\text { dos filhos, valores em educação, educação ambiental, entre outros. }\end{array}$ \\
\hline vi & Cultura & $\begin{array}{l}\text { Avaliar as tradições locais, festivais, valores nucleares, participação em eventos culturais, oportunidades de desenvolver } \\
\text { capacidades artísticas, além da discriminaç̃ão por causa de religião, raça ou gênero. }\end{array}$ \\
\hline vii & Meio ambiente & $\begin{array}{l}\text { Medir a percepç̃o dos cidadãos quanto à qualidade da água, do ar, do solo e da biodiversidade. Os indicadores incluem acesso } \\
\text { a áreas verdes, sistema de coleta de lixo etc. }\end{array}$ \\
\hline viii & Governança & $\begin{array}{l}\text { Avaliar como a população enxerga o governo, a mídia, o judiciário, o sistema eleitoral e a segurança pública em termos de } \\
\text { responsabilidade, honestidade e transparência. Também mede a cidadania e o envolvimento dos cidadãos com as decisões e } \\
\text { processos políticos. }\end{array}$ \\
\hline ix & Padrão de vida & Avaliar a renda individual e familiar, a segurança financeira, o nivel de dívidas, a qualidade das habitações etc. \\
\hline
\end{tabular}

Fonte: Elaborado a partir de Arruda (2009) e FIB (2015). 
periódicos reunidos no banco de dados da Scopus ${ }^{1}$. Observou-se que, desde os anos de 1983, registram-se discussões acerca do tema em diferentes áreas de estudo. A partir de meados dos anos de 2000, a temática se tornou mais latente nas pesquisas acadêmicas, de tal forma que o número de publicações, que era de 75 em 2006, passou para 400 em 2013.

Em se tratando de discutir felicidade, é importante destacar o trabalho do economista Giannetti (2002), que fez um estudo qualitativo sobre a felicidade, na forma de um diálogo leve e fluente, transitando entre o discurso econômico e a reflexão filosófica sobre a felicidade humana. Além dele, outras discussões sobre o tema no Brasil visam demonstrar a relação das variáveis socioeconômicas e o nível de desenvolvimento de determinado local. Esses trabalhos verificaram que tanto o IDH quanto o PIB precisam da complementação de outros indicadores para melhor avaliar o desempenho do desenvolvimento humano e econômico de uma região e/ou nação (Lustosa \& Melo, 2010).

Com o mesmo intuito, Sales et al. (2012) aplicaram o FIB na cidade de Lavras, em Minas Gerais, para avaliar se aspectos como sexo, idade, localização geográfica e escolaridade poderiam implicar nos diferentes níveis de felicidade dos indivíduos. Para tal, os autores aplicaram questionário a uma amostra da população local e utilizaram uma abordagem qualitativa-descritiva, no qual o método de análise empregado foi o da variância das médias das respostas. Os resultados derivados desse estudo indicaram que a felicidade dos indivíduos apresentava níveis distintos de acordo com o sexo, idade, localização geográfica e escolaridade.

Borelli \& Torres (2012) buscaram identificar se o FIB era complementar aos demais indicadores sociais e econômicos existentes. Para tal, utilizaram o método de análise fatorial e regressão, obtendo como resultado que o PIB era uma medida incompleta, uma vez que por si só não era capaz de representar o bem-estar social, e que o FIB era uma alternativa de complemento do PIB, ao indicar um caminho mais sustentável à felicidade.

\footnotetext{
${ }^{1}$ Scopus é uma base de dados de resumos e de citações revisados por pares na literatura, em que estão reunidos dados de revistas científicas, livros e anais de congressos, oferecendo uma visão abrangente da produção de pesquisas do mundo nas áreas de ciência, tecnologia, medicina, ciências sociais, artes e humanidades (Scopus, 2015).
}

Especificamente, para o Estado do Paraná, Shikida et al. (2004) procuraram avaliar a relação da felicidade com a economia a partir de uma amostra de agricultores participantes do Show Rural de 2004, evento ocorrido anualmente em Cascavel. Ao verificar os itens para a felicidade que mais se destacaram, inferiu-se que a variável economia estava entre os três mais importantes para a felicidade do agricultor, ao lado dos fatores saúde e família.

Em análise posterior para o mesmo município, Rodrigues \& Shikida (2005) avaliaram a relação da felicidade com o dinheiro (renda e/ou bens) por meio da aplicação de questionário. Como principais resultados, mais uma vez a saúde foi destaque, seguida da família, realização profissional/emprego, dinheiro/ renda/bens, realização no amor, paz/tranquilidade. E, em 2008, Shikida verificou a relação da felicidade com o dinheiro com base na literatura econômica. Como principais resultados, o autor identificou que a felicidade estava relacionada com a reflexão pessoal que envolvia o bem-estar derivado da utilização e do acesso aos produtos e serviços. Contudo, para o indivíduo possuidor de altas rendas, o dinheiro não acrescentava felicidade, mas, no outro extremo, o de recursos escassos, mais dinheiro dava uma expressiva contribuição à felicidade das pessoas.

Percebe-se que, nesses estudos, os pesquisadores tentaram identificar quais os fatores que mais influenciavam na felicidade dos indivíduos. 0 presente trabalho somará aos já existentes sobre o tema felicidade e, por meio da pesquisa de campo, identificará quais são os fatores que mais influenciam na felicidade dos trabalhadores de Cascavel. A metodologia adotada para esse propósito está descrita na próxima seção.

\section{Metodologia e fonte de dados}

A elaboração deste trabalho utilizou-se: da pesquisa bibliográfica, para fins de contextualização e definição do tema proposto; de dados secundários obtidos do IPARDES, para caracterização socioeconômica do local de estudo (Cascavel); da técnica de levantamento, ou survey, pela qual foram coletados dados com a população para a obtenção de informações quanto aos aspectos da felicidade dos trabalhadores do município e às variáveis determinantes para isso. Desse modo, do ponto de vista da abrangência da pesquisa, pode-se classificá-la como qualitativa, pois, por meio da análise 
de questionário aplicado in loco, identificou-se e discutiu-se uma população específica, representativa da comunidade trabalhadora cascavelense.

0 levantamento dos dados foi realizado no primeiro trimestre de 2015 por intermédio da aplicação direta de questionário a pessoas de diferentes localidades do município de Cascavel, focando, especificamente, nos que estão engajados no mercado de trabalho. O tamanho da amostra a ser analisada, isto é, quantas pessoas deveriam ser entrevistadas para compor uma amostragem estatisticamente significativa, foi calculado a partir da Fórmula 1 apresentada em Barbetta (2012, p. 58), dada por:

$n_{o=} 1 /\left(\mathrm{E}_{0}\right)^{2}$

Em que: $n_{o=}$ tamanho da amostra; E=erro amostral tolerável.

A amostra aleatória foi retirada considerando uma população ocupada total que, segundo o IPARDES (2015), era de 153.514 mil pessoas, considerando as áreas urbana e rural do município, admitindo-se um erro de até $10 \%$, com $90 \%$ de probabilidade. Para compor a amostra, foram consideradas apenas pessoas que estavam com idade acima de 16 anos, tendo em vista a idade limite para inserção no mercado de trabalho. Com base nessa fórmula, definiu-se que deveriam ser entrevistadas pelo menos 100 pessoas. A amostra foi definida de forma a compor entrevistados de todas as classes sociais, homens e mulheres, diferentes faixas etárias e níveis de escolaridade. No total, foram respondidos 127 questionários, dos quais 112 eram pessoas trabalhadoras, o que permitiu uma análise confiável e suficiente estatisticamente.

Para compor o FIB de Cascavel, foram selecionadas as variáveis indicadas no Quadro 2 e, a partir delas, elaboradas as questões que compuseram o questionário aplicado no município.

O questionário foi elaborado de modo a incorporar todas as dimensões do FIB. Sua estrutura contou com 46 questões, das quais 45 eram questões fechadas e direcionadas. A outra questão era aberta e solicitava que o indivíduo indicasse o que o deixava mais feliz. A estrutura completa dessa ferramenta pode ser conferida no Anexo 1. De posse dos dados, aplicou-se a estatística descritiva para a discussão.

\section{Felicidade interna bruta da população trabalhadora do município de Cascavel/PR}

A Tabela 1 apresenta a caracterização da amostra, ou seja, as principais características sociais e demográficas da população entrevistada. Durante as entrevistas, buscou-se mesclar o máximo possível os entrevistados com relação a sexo e idade, para assim captar as mais variadas informações.

Do total de entrevistados, $58 \%$ eram do sexo feminino, e 42\%, do sexo masculino. Em relação à faixa etária dos indivíduos, 35\% tinham entre 21 e 30 anos; $22 \%$, entre 16 e 20 anos; $17 \%$, de 31 a 40 anos; $26 \%$, acima de 41 anos.

Quadro 2 - Composição do indicador de Felicidade Interna Bruta (FIB) e as variáveis selecionadas para a pesquisa

\begin{tabular}{|l|l|}
\hline \multicolumn{1}{|c|}{ Dimensões } & \multicolumn{1}{c|}{ Variáveis selecionadas para a pesquisa } \\
\hline Bem-estar psicológico & Otimismo, estresse, satisfação e preocupação com o trabalho, infelicidade ou tristeza, atividades religiosas. \\
\hline Saúde & Prática de exerćicios físicos, adesão aos planos de saúde particulares, consumo de remédios etc. \\
\hline Uso do tempo & $\begin{array}{l}\text { Quantidade de horas trabalhadas na semana, de horas gastas no trânsito para ir e voltar ao trabalho diariamente, de horas de } \\
\text { lazer por semana, envolvimento com o trabalho. }\end{array}$ \\
\hline Vitalidade comunitária & Participação em grupos sociais, ajuda comunitária, tempo de morada na cidade. \\
\hline Educação & Nível de escolaridade, qualidade e infraestrutura da educação. \\
\hline Culfura & Cor ou raça, participação de grupos sociais, envolvimento religioso. \\
\hline Meio ambiente & Acesso à agua potável, à energia elétrica, a meio de transporte, à rede de esgoto, à rua pavimentada. \\
\hline Governança & Qualidade/confiança na administração pública, obrigaç̃oes eleitorais. \\
\hline Padrão de vida & $\begin{array}{l}\text { Renda recebida em salários mínimos, tipo de residência (alvenaria ou madeira), tamanho da família, vínculo com o domićlio, } \\
\text { acesso a transferências de renda do governo. }\end{array}$ \\
\hline
\end{tabular}

Fonte: Elaborado pelos autores (2015). 
Tabela 1 - Distribuição sociodemográfica dos moradores entrevistados de Cascavel, no Paraná, segundo o sexo, faixa etária, estado civil, escolaridade e região domiciliar

\begin{tabular}{|c|c|c|c|}
\hline Variáveis & Características & Total & $\%$ \\
\hline \multirow[t]{2}{*}{ Sexo } & Feminino & 74 & 0,58 \\
\hline & Masculino & 53 & 0,42 \\
\hline \multirow[t]{5}{*}{ Faixa etária } & 16 a 20 anos & 28 & 0,22 \\
\hline & De 21 a 30 anos & 45 & 0,35 \\
\hline & De 31 a 40 anos & 21 & 0,17 \\
\hline & De 41 a 50 anos & 19 & 0,15 \\
\hline & Mais de 50 anos & 14 & 0,11 \\
\hline \multirow[t]{4}{*}{ Estado civil } & Solteiro & 54 & 0,43 \\
\hline & Casado & 65 & 0,51 \\
\hline & Divorciado & 5 & 0,04 \\
\hline & Viúvo & 3 & 0,02 \\
\hline \multirow[t]{11}{*}{ Escolaridade } & Ensino fundamental completo & 14 & 0,12 \\
\hline & Ensino fundamental incompleto & 13 & 0,11 \\
\hline & Ensino médio completo & 23 & 0,19 \\
\hline & Ensino médio incompleto & 5 & 0,04 \\
\hline & Ensino superior completo & 20 & 0,17 \\
\hline & Ensino superior incompleto & 31 & 0,26 \\
\hline & Especialização & 11 & 0,09 \\
\hline & Mestrado & 2 & 0,02 \\
\hline & Doutorado & 2 & 0,02 \\
\hline & Sem escolaridade & 1 & 0,01 \\
\hline & Não responderam & 6 & 0,05 \\
\hline \multirow{6}{*}{$\begin{array}{l}\text { Região urbana } \\
\text { domiciliar }\end{array}$} & Oeste & 24 & 0,19 \\
\hline & Leste & 20 & 0,16 \\
\hline & Norte & 18 & 0,14 \\
\hline & Sul & 48 & 0,38 \\
\hline & Centro & 8 & 0,06 \\
\hline & Zona rural & 9 & 0,07 \\
\hline
\end{tabular}

Fonte: Elaborado pelos autores com base nos resultados da pesquisa (2015).

Os entrevistados eram, em sua maioria, casados (51\%), seguido dos indivíduos solteiros (43\%). 0 nível de escolaridade majoritário era referente aos que estavam cursando a faculdade, isto é, com ensino superior incompleto (27\%), e àqueles que tinham o ensino médio completo (19\%). Quanto à localização no município das residências dos entrevistados, elas foram assim distribuídas: $38 \%$ na região sul; $19 \%$ na região oeste; $30 \%$ nas regiões leste e norte; $6 \%$ no centro. Quando verificou-se a zona de residência, 93\% eram da área urbana.

Identificadas as principais características da população entrevistada, o próximo passo foi analisar as respostas dos questionários conforme as atribuições dadas pelas dimensões do FIB, optando por: bem-estar psicológico, saúde, uso do tempo, vitalidade comunitária, educação, cultura, governança e padrão de vida. A categoria meio ambiente foi agrupada à dimensão 
padrão de vida, uma vez que as questões elaboradas se enquadravam tanto em uma quanto em outra.

\section{A dimensão bem-estar psicológico}

A primeira dimensão a ser apresentada é a do bem-estar psicológico. Segundo o FIB, essa dimensão avalia o grau de satisfação e de otimismo que cada indivíduo tem em relação à sua própria vida. Os indicadores incluem a prevalência de taxas de emoções tanto positivas quanto negativas e analisam autoestima, sensação de competência, estresse e atividades espirituais.

Dos entrevistados, $49 \%$ sentiam-se sempre otimistas com relação ao modo como viam a vida, e $50 \%$, às vezes. No geral, $97 \%$ eram otimistas. No entanto, $80 \%$ disseram estar sob estresse, tentando cumprir mais tarefas do que podiam fazer, e, desse total, 29\% estavam sempre nessa condição.

Questionados sobre o sentimento de infelicidade ou de depressão, 3\% disseram que sempre se sentiam deprimidos, tristes ou infelizes; $39 \%$, às vezes; $35 \%$, raramente; $23 \%$ nunca se consideravam dessa forma. Do total de entrevistados, $88 \%$ (112) estavam trabalhando, e $12 \%$, não. Dentre os trabalhadores, 68 deles $(60,7 \%)$ apenas trabalhavam, enquanto que 44 (39,3\%) tinham dupla jornada, isto é, trabalhavam e estudavam. Foi perguntando ainda como a pessoa se sentia em relação ao trabalho que realizava, no intuito de captar se ela estava satisfeita ou não com a ocupação: $43 \%$ disseram estar felizes no trabalho, $28 \%$ eram muito felizes com o que faziam e $7 \%$ deles se julgaram pouco feliz. Apenas um deles declarou se sentir totalmente insatisfeito.

Todavia, ao perguntar se, com todos os esforços e resultados do trabalho realizado, o indivíduo considerava que a sua remuneração era adequada, $78 \%$ achavam que não. Ainda, para analisar o grau de envolvimento da pessoa com a sua atividade profissional, foi questionado se ela ficava preocupada com coisas do trabalho quando estava fora do ambiente de serviço. Do total de entrevistados, $60 \%$ disseram que sim, dos quais $16 \%$ estavam sempre nessa condição, e outros $25 \%$ responderam que nunca se sentiam assim.

Nessa mesma dimensão, questionou-se a existência da prática de atividades espirituais. Aproximadamente $49 \%$ dos entrevistados disseram frequentar semanalmente lugares de importância espiritual ou religiosa, 7\% iam diariamente e 44\% disseram nunca ou raramente participar de eventos dessa natureza.

Foi possível observar que a maioria dos entrevistados se considerava otimista, apesar de parte deles viverem sob estresse, tentando cumprir mais tarefas do que podiam fazer, terem dupla jornada entre trabalho e estudo, e considerarem a remuneração recebida inadequada aos esforços que realizavam.

\section{A dimensão saúde}

A dimensão saúde mede a eficácia das políticas de saúde com critérios como autoavaliação da saúde, invalidez, padrões de comportamento arriscados, exercícios, sono, nutrição etc. Nesse quesito, os entrevistados foram perguntados quanto ao consumo de bebidas e cigarro, ao consumo de remédios, à prática de exercícios e à qualidade do sono.

Dos respondentes, 3\% declararam consumir bebidas alcoólicas diariamente; $24 \%$ disseram que sempre consumiam; $47 \%$; ocasionalmente; $26 \%$, nunca. Quanto ao consumo de cigarros, $86 \%$ dos entrevistados declararam não fumar e $9 \%$ fumavam sempre ou diariamente, o que caracteriza o vício e a necessidade de consumo constante.

Quando perguntado sobre a ocorrência de doenças na família, incluindo o entrevistado: $12 \%$ responderam que havia casos de obesidade, considerada pelo estudo como "doença"; $37 \%$, de hipertensão; 28\%, de diabetes; $19 \%$ tinham membros na família que apresentavam doenças cardíacas; 30\% registravam colesterol, além de outros casos não especificados. Ressalta-se que alguns entrevistados apontaram mais de um tipo de doença na família. No entanto, $70 \%$ disseram não possuir plano de saúde particular, o que indica a dependência total do sistema público de saúde ou de consultas particulares. Além disso, $31 \%$ deles disseram tomar remédios frequentemente.

0 exercício físico está associado à qualidade de vida e, inclusive, reflete na qualidade do sono das pessoas. Isso está atrelado ao humor e ao desempenho dos indivíduos. Dos entrevistados, quando questionados com relação à frequência de atividade física: 19\% responderam que nunca praticavam; 34\%, raramente; $17 \%$, diariamente; $31 \%$, semanalmente. Ao perguntar para o indivíduo se ele tinha boas noites de sono, tranquilo e profundo: $10 \%$ responderam que raramente; $2 \%$ disseram nunca dormir profundamente; $66 \%$ 
assinalaram que sim; $36 \%$ afirmaram que às vezes tinham um sono bom, tranquilo e profundo.

De maneira geral, a saúde dos trabalhadores cascavelenses se encontrou em bom estado, embora tenha sido apontada a existência de casos em que o entrevistado ou a sua família possuía doenças como diabetes, hipertensão, obesidade e colesterol.

\section{A dimensão uso do tempo}

A terceira dimensão do FIB refere-se ao uso do tempo, um dos mais significativos fatores na qualidade de vida, especialmente para lazer e socialização com família e amigos. A gestão equilibrada do tempo é avaliada incluindo tempo no trânsito, no trabalho, nas atividades educacionais, entre outros.

Com perguntas elaboradas a partir dessas colocações, obteve-se que, do grupo entrevistado: 49\% dedicavam mais de 2 horas na semana para lazer; $24 \%$, de 1 a 2 horas; $20 \%$, até 1 hora; $8 \%$ disseram não ter tempo para o lazer.

Com relação aos trabalhadores e ao tempo destinado ao labor, $27 \%$ trabalhavam mais de 40 horas por semana, e $51 \%$, de 21 a 40 horas. Ressalta-se que não foram questionados sobre a prática do trabalho doméstico realizado nos lares, principalmente pelas mulheres. Dos entrevistados que declararam trabalhar, 89\% gastavam até 1 hora diariamente para ir e voltar do trabalho; $11 \%$, de 1 a 2 horas; $4 \%$, mais de 3 horas. A maioria desses trabalhadores morava em bairros diferentes de onde se localizava o trabalho, por isso alguns precisavam esperar por mais de um ônibus e passar por diferentes terminais para chegar no horário.

0 meio de transporte mais utilizado para ir e voltar do trabalho era o veículo particular, com $38 \%$, seguido do transporte coletivo (ônibus), com 33\%. Outras formas, como o uso de motocicleta, bicicleta ou carona solidária, somaram 35\%. Além disso, 23\% iam a pé para o trabalho, indicando que moravam próximo à atividade. Alguns usavam mais de uma modalidade para esse fim. Perguntado sobre a fadiga resultante da atividade laboral, $17 \%$ se sentiam tão cansados depois do trabalho, que não conseguiam dedicar tempo ao que gostariam, como a prática de um lazer, ficar mais com a família e amigos, sair para distração, entre outras atividades; $44 \%$ responderam que às vezes se sentiam assim; $24 \%$, raramente; $18 \%$ nunca se identificavam nessa condição.
Conforme apontado pelos dados obtidos para a dimensão uso do tempo, os pesquisados despendiam, semanalmente, para a atividade laboral, somada à distância a ser percorrida diariamente e ao fluxo de veículos no trajeto de idas e vindas do trabalho, um tempo que poderia ser utilizado para outros fins, especialmente para o lazer.

\section{A dimensão vitalidade comunitária}

A vitalidade comunitária é a quarta dimensão do FIB. Essa variável foca nos relacionamentos e interações nas comunidades, examina o nível de confiança, a sensação de pertencimento, a vitalidade dos relacionamentos afetivos, a segurança em casa e na comunidade, a prática de doação e de voluntariado. Nesse sentido, perguntou-se aos entrevistados se eles costumavam participar de algum grupo social, como igrejas, Rotary, associações, clubes, grupos de amigos, entre outros: $53 \%$ responderam que sim; 37\%, não; outros $10 \%$, às vezes. Além disso, $56 \%$ deles disseram que interagiam com a comunidade, participando de festas locais e eventos sociais. Os demais não participavam ou não responderam.

Sobre a doação, fez-se uma pergunta para saber se o indivíduo costumava praticar algum tipo de ajuda a outras pessoas. Do total, $75 \%$ disseram que sim, $23 \%$ o faziam raramente, $9 \%$ aju davam sempre e os demais 25\% declararam nunca realizar esse tipo de ação. Quando questionados sobre como se sentiam ao realizar trabalhos sociais, dos que praticavam tais ações, $43 \%$ responderam que isso os deixava felizes e $29 \%$ se sentiam muito felizes. Nessa dimensão também se analisou o sentimento de pertence ao lugar em que se vivia. Registrou-se que, dentre os entrevistados, 65\% moravam havia mais de 15 anos em Cascavel, e 9\%, de 10 a 15 anos, ou seja, a maioria (74\%) morava no município havia mais de 10 anos, levando ao entendimento de que se sentiam satisfeitos com o local em que moravam.

Quanto à prática de atividades em comunidade, identificou-se que a maioria dos entrevistados realizava ou participava de alguma atividade em grupo, quer em associações de moradores, Rotary, clubes, ou outras formas. Tal ato pode estar refletido no alto percentual de ajuda à comunidade praticada por eles. 


\section{A dimensão educação}

A educação representa a quinta dimensão do FIB, e nessa variável selecionaram-se fatores associados ao ato de estudar ou não e à qualidade da educação que recebiam. Apenas 36\% dos entrevistados estudavam, dos quais $40 \%$ se sentiam satisfeitos ou muito satisfeitos com a qualidade das aulas e a infraestrutura da instituição em que estudavam ou estudaram. Já os insatisfeitos somaram $23 \%$. Os demais (37\%) não souberam responder, talvez por não estudarem mais ou não quiseram se manifestar a respeito.

\section{A dimensão cultura}

A sexta dimensão, cultura, complementa a quarta dimensão - vitalidade comunitária -, pois os aspectos culturais impactam diretamente na convivência em comunidade. Aqui, incorporaram-se as questões relacionadas à cor ou raça dos indivíduos e à discriminação.

Dos entrevistados, $55 \%$ se autodeclararam brancos, 28\%, pardos, 9\%, negros; amarelos e os que não souberam responder somaram 8\%. Quando perguntado se já sofreu algum tipo de discriminação, quase a metade deles (44\%) disse que sim, dos quais $6 \%$ já sofreram discriminação racial, $9 \%$, social, $8 \%$, por gênero, $16 \%$, pelo biótipo físico, e $9 \%$, preconceito econômico. No total, $56 \%$ disseram que nunca sofreram com nenhum tipo de discriminação.

Dentre as vítimas de preconceito, algumas delas receberam mais de uma forma de discriminação. É importante ressaltar que esta pode ser interpretada pelos indivíduos como uma não aceitação ao grupo social, como se houvesse padrões estabelecidos. Por terem características diferentes desses padrões, eles se tornam excluídos, afetando diretamente o bem-estar psíquico das pessoas e, consequentemente, o grau de sentimento de felicidade.

\section{As dimensões meio ambiente e padrão de vida}

Considerando que as características definidas para a dimensão meio ambiente estão também associadas ao domicílio do indivíduo, optou-se em agregá-la com a dimensão padrão de vida, que, por sua vez, entre outras variáveis, analisa as condições das residências.
Além disso, incluem-se também a avaliação da renda individual e familiar, a segurança financeira, o nível de dívidas, a qualidade das habitações, entre outros pontos. Nesse caso, os entrevistados foram perguntados sobre a renda mensal familiar, condição e tipo de residência, acesso à água encanada, luz elétrica, coleta regular de lixo, esgoto e rua pavimentada.

Analisando o tipo da residência, a casa de 77\% deles era de alvenaria, 8\%, de madeira, e 15\% (19), composta pelos dois materiais. Além disso, 62\% moravam em casa própria, $31 \%$ pagavam aluguel e $6 \%$ moravam em residência cedida. Identificou-se ainda que $10 \%$ das residências não tinham coleta de lixo regular, $20 \%$ disseram que não eram atendidos pela rede de esgoto e $9 \%$ declararam não ter a rua de sua residência pavimentada.

Ao perguntar quantas pessoas moravam na residência, 78\% dos entrevistados moravam com duas a quatro pessoas; $13 \%$, com cinco; um entrevistado, com seis; e um, com oito. Diante disso, a próxima pergunta feita foi: Qual a renda familiar mensal? Deles, 45\% responderam que somavam mais de três salários mínimos; $22 \%$ ganhavam cerca de três salários mínimos mensais; 9\%, um salário mínimo ao mês. Do total, 13 indivíduos recebiam transferência de renda do governo para complemento da renda familiar. Ainda, dos entrevistados, 63\% disseram usar o carro particular como meio de transporte no dia a dia, enquanto que $35 \%$ utilizavam o transporte coletivo. Outras formas, como o uso de motocicletas, bicicletas ou andar a pé, foram apontadas por $20 \%$ dos entrevistados.

Verificando as características domiciliares e de saneamento, observou-se que a maioria das residências era de alvenaria e própria, mas havia uma defasagem no atendimento e na prestação de serviços relacionados ao saneamento básico aos moradores da cidade de Cascavel, pois a coleta de lixo não era regular em 10\% das residências e $20 \%$ delas não eram assistidas pela rede de esgoto municipal.

\section{A dimensão governança}

A oitava dimensão, denominada governança, avalia como a população enxerga o governo, a mídia, o judiciário, o sistema eleitoral e a segurança pública, em termos de responsabilidade, honestidade e transparência. Também mede a cidadania e o envolvimento dos cidadãos com as decisões e processos políticos. 
Para compô-la, perguntou-se aos indivíduos como eles qualificavam, de modo geral, a ação dos governos nos últimos 12 meses e sobre o seu envolvimento com a esfera pública.

Do total, $83 \%$ dos entrevistados afirmaram que cumpriram com sua obrigação eleitoral, votando nas últimas eleições, mas apenas 59\% disseram que discutiam políticas com familiares ou amigos. No entanto, $69 \%$ consideravam que os governos tiveram um péssimo desempenho, e 27\%, atuação regular. Quanto à administração pública do município de Cascavel, esta sofreu rejeição/não confiança da grande maioria dos entrevistados (89\%). Ademais, quando questionados sobre a sensação de segurança onde moram, 33\% sentiam-se pouco seguros, e $11 \%$, inseguros.

A última questão que compôs o questionário perguntava ao indivíduo o que o deixava mais feliz. Cada entrevistado apontou até três fatores. Para facilitar a exposição, as expressões foram agrupadas nas categorias que estão apresentadas na Figura 1. 0 tamanho de cada bolha da Figura 1 ilustra as categorias que foram mais vezes apontadas como motivos para a felicidade dos indivíduos entrevistados.

A família foi apontada pela maioria das pessoas na entrevista, com 71 citações. Os indivíduos disseram que estar com membros da família, o bem-estar e o sucesso de familiares, a paz na família, o orgulho dos entes eram fatores que os deixavam mais felizes. Na sequência apareceram o lazer e a prática de atividades físicas, que englobavam tarefas como praticar esportes diversos, ouvir música, tirar fotos e fazer passeios, declarados por 32 pessoas. Estar com amigos/ter amizades ocupou a terceira posição no ranking dos fatores promotores da felicidade dos entrevistados, com expressões correlacionadas citadas por 24 deles. Na quarta posição estava o dinheiro com aquisições de bens materiais, e incluía ter dinheiro em espécie, especialmente para satisfazer às necessidades e manter as contas em dia, além da aquisição da casa própria.

Na sequência vinham as realizações pessoais e profissionais, que englobavam o reconhecimento por mérito no trabalho, as conquistas pessoais e o sucesso nos estudos, mencionados por 21 pessoas. 0 trabalho foi motivo de felicidade para 18 pessoas, ocupando a sexta colocação na escala, seguido de bons sentimentos como amor, afeto e carinho. Nessa categoria foram incluídos fatores como namoro, abraços, dar e receber carinhos, brincar com animais.

Descansar, viajar e estar de férias foram apontados por 16 indivíduos como motivos que os deixavam felizes. Atividades que envolviam ir à igreja, visitar doentes, ajudar os outros, ver outras pessoas felizes e bem, paz espiritual, esperança de melhorias, compaixão, cheiros bons, ser solidário e caridoso para com os outros, estar com ou ter saúde também foram expressões bastante indicadas como propulsores de felicidade dos entrevistados.

0 Quadro 3 foi montado com as variáveis apontadas pelos entrevistados como fatores impactantes no seu nível de felicidade, de acordo com cada uma

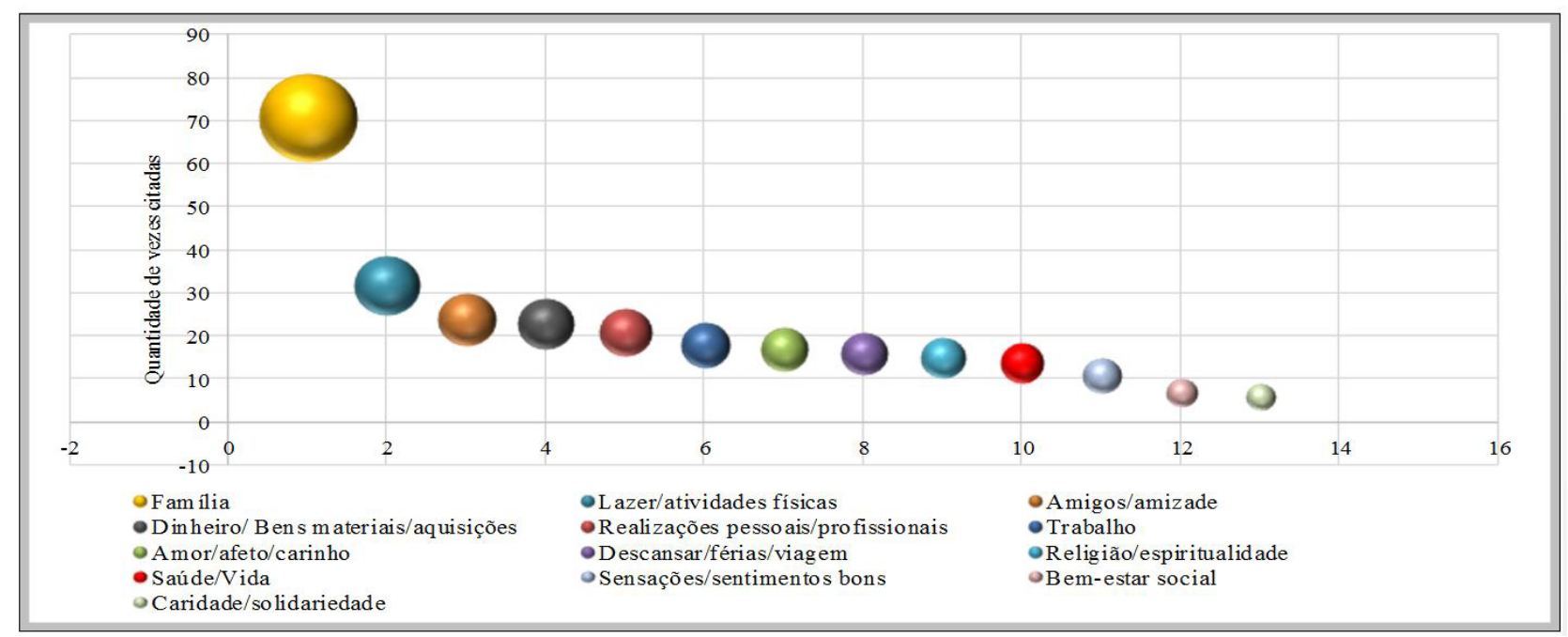

Figura 1 - Fatores indicados pelos entrevistados de Cascavel, no Paraná, como fonte de felicidade Fonte: Elaborado pelos autores com base nos resultados da pesquisa (2015). 
Quadro 3 - Associação dos fatores citados pelos entrevistados de Cascavel, no Paraná, como fonte de felicidade às dimensões medidas pelo Felicidade Interna Bruta (FIB)

\begin{tabular}{|c|c|c|}
\hline $\begin{array}{l}\text { Dimensões } \\
\text { do FIB }\end{array}$ & $\begin{array}{l}\text { Componentes } \\
\text { do FIB }\end{array}$ & Fatores citados pelos entrevistados como fonte de felicidade \\
\hline $\mathbf{i}$ & Bem-estar psicológico & $\begin{array}{l}0 \text { bem-estar da família, sucesso dos filhos ou parceiros, amizades, namorar, amor, sexo, brincar com animais, ir à igreja, ler a } \\
\text { bíblia, paz espiritual, Deus, a religião, realizaçōes pessoais e profissionais, reconhecimento pessoal e profissional, conquistas, } \\
\text { cheiros bons, ter compaixão, ser útil aos outros, aijudar os outros. }\end{array}$ \\
\hline ii & Saúde & Estar com saúde, saúde da família, a vida, comer. \\
\hline iii & Uso do tempo & $\begin{array}{l}\text { Estar com a família, estar com amigos, namorar, andar de skate, praticar atividade física, exercitar, festas, fotografar, futebol, } \\
\text { passear, leitura, livro, momentos de lazer, música, pescar, brincar com o cachorro, folga do trabahho, dormir, relaxar. }\end{array}$ \\
\hline iv & Vitalidade comunitária & $\begin{array}{l}\text { Aiudar os outros, servicos comunitários, tratar bem as pessoas, bem-estar da sociedade, felicidade alheia, visitar doentes, ser } \\
\text { solidário com os outros, ir à igreja. }\end{array}$ \\
\hline $\mathbf{v}$ & Educação & Estudar, êxito nos estudos, a faculdade. \\
\hline vi & Cultura & Festas, cantar, música, fotografar, futebol, ir à igreja. \\
\hline vii & Meio ambiente & Praia, pescar, contato com plantas e flores, respirar ar puro, contemplar a natureza. \\
\hline viii & Governança & Melhor governo, melhora na saúde, combate à pobreza. \\
\hline ix & Padrão de vida & 0 trabalho, trabahar, a casa própria, a moradia, viajar, fazer compras, boa alimentacāou, contas em dia, praia. \\
\hline
\end{tabular}

Fonte: Elaborado pelos autores com base nos resultados da pesquisa (2015).

das dimensões do FIB. Dessa forma, na dimensão bem-estar psicológico, os entrevistados consideraram como importante o bem-estar da família, o sucesso pessoal e de familiares, ir à igreja, ler a bíblia, a paz espiritual, o reconhecimento pessoal e profissional, as conquistas pessoais e de familiares, os cheiros bons, compadecer-se e ajudar as pessoas, ser útil aos outros. Algumas dessas características também estavam relacionadas à dimensão vitalidade comunitária, que registrou os aspectos associados à convivência e ao relacionamento em sociedade.

Os fatores associados à educação, como ter êxito nos estudos e estar matriculado em uma universidade, também foram relatados pelos entrevistados. Participar de atividades culturais ou correlatas ao meio ambiente, festas, ir a locais que possibilitassem o contato com ar puro e contemplar a natureza também foram apontados pela população questionada. Por fim, dentre as respostas de atributos à governança, relatou-se a necessidade de um governo melhor, mais atuante para a melhora no sistema de saúde e no combate à pobreza. Já com relação ao padrão de vida, o fato de ter um trabalho, a possibilidade de viajar, a moradia adequada, a boa alimentação e o pagamento dos compromissos em dia foram alguns dos aspectos mencionados.

\section{Considerações finais}

Este estudo buscou identificar quais fatores que mais influenciavam na felicidade dos trabalhadores do município de Cascavel. Para tal, utilizaram-se a metodologia proposta pelo índice FIB e a aplicação de um questionário para obtenção dos dados. Para o FIB da população entrevistada, foi considerada e analisada cada uma das dimensões que esse indicador propõe: o bem-estar psicológico, a saúde, o uso do tempo, a vitalidade comunitária, a educação, a cultura, a governança e o padrão de vida. A desagregação das dimensões permitiu melhor entendimento e enriqueceu o conhecimento sobre o fenômeno felicidade.

Conclui-se que a abordagem sugerida pelas dimensões do indicador FIB foi válida para este estudo sobre a felicidade dos trabalhadores cascavelenses, uma vez que, ao associar os fatores indicados pelos próprios entrevistados como fonte de sua felicidade a essas dimensões, percebeu-se que estavam de acordo com o que apregoava cada uma delas. Assim, pode-se considerar que o FIB está no caminho certo quando inclui, em sua abordagem sobre a felicidade humana, fatores além daqueles ligados ao âmbito econômico, capazes de melhor refletir a qualidade de vida e a satisfação das pessoas. 
Diante do que as pessoas apontaram como resposta à pergunta sobre o que as deixavam felizes, identificou-se maior preferência por fatores não materiais, despontando, especialmente, aqueles associados à família, aos bons sentimentos, às boas práticas em sociedade, à saúde, à solidariedade e à espiritualidade. 0 dinheiro, não obstante, também foi um importante fator mencionado, principalmente pelo conforto e pelas possibilidades trazidas, como manter em dia as contas, garantindo a segurança financeira, mas não foi o item principal. Dessa forma, identificou-se que, para a população trabalhadora do município de Cascavel, a felicidade esteve na maioria das respostas associada às relações sociais e familiares.

Cabe ressaltar que, neste trabalho, o objetivo central dos autores foi o de apenas identificar, por meio do questionário, e apresentar quais seriam os fatores que os pesquisados apontariam como sua fonte de felicidade e se esses fatores estariam de acordo com as dimensões do FIB, não se prendendo em categorizar e dar às dimensões pesos diferentes na participação da geração de felicidade dos indivíduos. Assim, o próximo desafio é, utilizando-se das respostas indicadas nas questões representativas das dimensões, construir um índice, considerando as ponderações necessárias e devidamente adequadas, que seja capaz de refletir, mensurar e indicar o nível de felicidade da população em estudo, o que se constituirá em uma pesquisa futura. Além desta, outras discussões também podem ser sugeridas para trabalhos futuros, como comparar o município de Cascavel com os municípios do seu entorno e, ainda, analisar quais seriam os resultados para a população trabalhadora da área urbana em relação à área rural.

\section{Referências}

Arruda, M. (2009). As nove dimensões do FIB. São Paulo: Instituto Visão Futuro Parque Ecológico. Recuperado em 10 de janeiro de 2015, de www.fbes.org.br/biblioteca22/ arruda_dimensoes_fib.doc

Banco Mundial. (2011). Dados: 2011. Recuperado em 10 de junho de 2015, de http://datos.bancomundial.org/ indicador/NY.GDP.MKTP.CD/countries

Barbetta, P. A. (2012). Estatística aplicada às ciências sociais (8a ed.). Florianópolis: UFSC.
Borelli, E., \& Torres, A. R. (2012). O desafio da métrica da felicidade para um desenvolvimento sustentável. In Anais do XVI Encontro Internacional sobre Gestão Empresarial e Meio Ambiente (p. x-y). São Paulo: FEA-USP.

Felicidade Interna Bruta - FIB. (2015). FIB na teoria. Recuperado em 10 de janeiro de 2015, de http://www. felicidadeinternabruta.org.br/

Giannetti, E. (2002). Felicidade: diálogos sobre o bem-estar na civilização (1a ed.). São Paulo: Companhia das Letras.

Helliwell, J., Layard, R., \& Sachs, J. (2013). World happiness report. Columbia: Columbia University. Recuperado em 30 de janeiro de 2015, de http://issuu,com/earthinstitute/ docs/worldhappinessreport2013_online

Instituto Paranaense de Desenvolvimento Econômico e Social - IPARDES. (2015). Caderno do município de Cascavel: 2015. Curitiba: IPARDES. Recuperado em 10 de janeiro de 2015, de http://www.ipardes.gov.br

Louette, A. (2007). Indicadores de nações: uma contribuição ao diálogo da sustentabilidade: gestão do Conhecimento (1a ed.). São Paulo: Willis Harman House.

Lustosa, A. E., \& Melo, L. F. (2010). Felicidade Interna Bruta (FIB): índice de desenvolvimento sustentável. Goiás: Instituto Mauro Borges de Estatísticas e Estudos Socioeconômicos. Recuperado em 10 de janeiro de 2015, de http://www. seplan.go.gov.br/sepin/pub/conj/conj14/artigo05.pdf

Rodrigues, O. A., \& Shikida, P. F. A. (2005). Economia e felicidade: elementos teóricos e evidências empíricas. Pesquisa \& Debate, 16(1), 80-120. Recuperado em 10 de janeiro de 2015, de http://revistas.pucsp.br/index.php/ rpe/article/view/11894

Roncolato, M. (2013). O mapa da Felicidade no Mundo. Revista Galileu, Rio de Janeiro. Recuperado em 25 de janeiro de 2015, de http://revistagalileu.globo. com/Revista/Common/0,EMI342521-17770,00O+MAPA+DA+FELICIDADE+NO+MUNDO.html

Sales, A. P., Ferreira, C. A., Veroneze, R. B., Rezende, L. T., Costa, A. P., \& Sette, R. S. (2012). Felicidade Interna Bruta: um estudo na cidade de Lavras - MG. In Anais do XXXVI Encontro da Associação Nacional de Pós-Graduação e Pesquisa em Administração (p. 1-16). Rio de Janeiro: EnANPAD.

Sales, A., Costa, A., Veronese, R., Ferreira, C., \& Resende, L. (2013). Felicidade interna bruta: aplicação e discussão no contexto de cidades de porte médio brasileiras. Revista Cade, 12(1), 59-82. Recuperado em 10 de janeiro de 2015, de http://editorarevistas.mackenzie.br/index.php/cade/ article/view/6330/4483 
Scopus. (2015). Amsterdam: Elsevier. Recuperado em 10 de janeiro de 2015, de http://www.scopus.com/

Shikida, P. F. A., Rodrigues, O. A., \& Braun, M. B. S. (2004). Economia e felicidade: uma análise dos agricultores participantes do Show Rural (Cascavel-PR). In Anais do XLII Congresso Brasileiro de Economia e Sociologia Rural - SOBER (p. 1-16). Cuiabá: SOBER.

Shikida, P. F. A. (2008). A gente não quer só dinheiro... a gente quer dinheiro e felicidade: notas e reflexões no contexto da Ciência Econômica. Ciências Sociais Aplicadas em Revista,
Marechal Cândido Rondon, 8(14), 47-60. Recuperado em 10 de janeiro de 2015, de http://e-revista.unioeste.br/ index.php/csaemrevista/article/view/3150

Visão do Futuro. (2015). Histórico do FIB. São Paulo: Visão do Futuro. Recuperado em 20 de janeiro de 2015, de http:// www.visaofuturo.org.br/pdfs2/Hist\%C3\%B3rico\%20 do\%20FIB.pdf

Recebido: Ago. 18, 2015

Aprovado: Dez. 11, 2015 
Anexo 1 - Questionário aplicado na pesquisa

1) Sexo: ( ) Feminino ( ) Masculino
2) Quantos anos você está?
( ) 16 a 20 anos
( ) De 21 a 30 anos
( ) De 31 a 40 anos
( ) De 41 a 50 anos
( ) Mais de 50 anos
3) Estado civil:
( ) Solteiro
( ) Casado
( ) União estável
( ) Divorciado
( ) Viúvo
4) Indique qual a localização do seu bairro?
( ) Oeste
( ) Leste
( ) Norte
( ) Sul Outros/Bairro:
5) $\mathbf{0}$ modo como vê a vida, você se considera uma pessoa otimista?
( ) Sempre
( ) Às vezes
( ) Raramente
( ) Nunca

6) Você se sente sob estress, tentando cumprir mais do que você pode fazer?
( ) Sempre
( ) Às vezes
( ) Raramente
( ) Nunca

7) Costuma consumir bebidas alcoólicas? ( ) Sempre

( ) Diariamente

( ) Ocasionalmente ( ) Nunca

8) Fuma? Com qual frequência? ( ) Sempre ( ) Diariamente

( ) Ocasionalmente ( ) Nunca

9) Possui plano de saúde? ( ) Sim ( ) Não

10) Na sua família há casos de doenças?
( ) Obesidade
( ) Hipertensão
( ) Diabetes
( ) Colesterol
( ) Nenhuma
( ) Doenças cardíacas
( ) Anemia
( ) Desnutrição
( ) Outras

11) Você toma algum remédio frequentemente? ( ) Sim

( ) Não

12) Você dorme bem, tranquilamente, com sono profundo?

( ) Sempre

( ) Às vezes

( ) Raramente

( ) Nunca

13) Com que frequência pratica atividade física?

( ) Diariamente

( ) Semanalmente

( ) Raramente

( ) Nunca

14) Quantas horas você trabalha na semana?

( ) Nenhuma ( ) Até 10

( ) 11 a 20

( ) 21 a 40

( ) Mais de 40

15) Qual o meio de transporte utilizado para ir ao trabalho?
( ) A pé
( ) Transporte coletivo
( ) Carro particular
( ) Carona solidária
( ) Bicicleta
( ) Motocicleta

16) Quanto tempo você gasta para ir e voltar do trabalho diariamente?
( ) Até meia hora
( ) De meia a 1 hora
( ) De 1 a 2 horas
( ) Mais de 2 horas

17) Quanto tempo destina ao lazer semanalmente?
( ) Nenhum
( ) Até meia hora
( ) De meia a 1 hora
( ) De 1 a 2 horas
( ) Mais de 2 horas

18) Você fica preocupado com coisas do trabalho quando não está trabalhando?

( ) Sempre ( ) Às vezes ( ) Raramente ( ) Nunca 
Anexo 1 - Continued...

19) Sente-se tão cansado depois do trabalho que não consegue dedicar tempo ao que gostaria: lazer, família, amigos, etc?

( ) Sempre ( ) Às vezes ( ) Raramente ( ) Nunca

20) Sente-se feliz trabalhando? ( ) Muito feliz $\quad$ ( ) Feliz $\quad$ ( ) Parcialmente feliz

( ) Pouco feliz ( ) Nada feliz

21) Qual a renda mensal da família?
( ) Sem renda
( ) Meio salário
( ) Um salário
( ) Dois salários
( ) Três salários
( ) Mais de três salários

22) Considerando todos os esforços e resultados do seu trabalho, você considera a sua remuneração adequada?

( ) Sim ( ) Não

23) Você tem acesso a algum programa de transferência de renda do Governo?

( ) Sim ( ) Não
24) Indique qual o tipo de sua residência?
( ) Alvenaria
( ) Madeira
( ) Mista
25) Qual é a condições do seu domicilio?
( ) Própria
( ) Alugada
( ) Cedida
( ) Invadida
( ) Financiada

26) Indique se possui os serviços básicos de saneamento:

( ) Água encanada

( ) Luz

( ) Coleta regular de lixo

( ) Esgoto

( ) Rua pavimentada

(asfaltada)

27) Quantas pessoas moram na sua residência?

(1)

(2)

(3)

(4)

(5)

(7) (8) (9) (>9)

28) Você participa de algum grupo social (igreja, comitês, Rotary, associações, clubes, etc)?
( ) $\mathrm{Sim}$
( ) Não
( ) Às vezes

29) Você participa de festas locais e eventos sociais em sua comunidade?

( ) Sim ( ) Não

30) Visita igreja ou outros lugares de importância espiritual e religiosa em sua comunidade?
( ) Diariamente
( ) Semanalmente
( ) Raramente
( ) Nunca

31) Com relação aos serviços comunitários, você pratica algum tipo de ajuda a outras pessoas?
( ) Sempre
( ) Às vezes
( ) Raramente
( ) Nunca

32) Sente-se feliz realizando trabalho social?

( ) Muito feliz

( ) Feliz

( ) Parcialmente feliz

( ) Pouco feliz

( ) Nada feliz

33) Quanto tempo mora em Cascavel?

( ) Menos de cinco anos

( ) De 5,1 a 10 anos
( ) De 10,1 a 15 anos
( ) Mais de 15

34) Qual o seu Grau de escolaridade:
( ) Ensino fundamental completo
( ) Ensino fundamental incompleto
( ) Especialização
( ) Ensino médio completo
( ) Ensino médio incompleto
( ) Mestrado
( ) Ensino superior completo
( ) Ensino superior incompleto
( ) Doutorado
35) É estudante? ( ) Sim ( ) Não

36) Sente-se satisfeito com a qualidade das aulas e a infraestrutura da entidade de ensino a qual frequenta?
( ) Muito satisfeito
( ) Satisfeito
( ) Pouco satisfeito
( ) Insatisfeito ( ) Não sabe responder 
Anexo 1 - Continued...

37) Qual a Cor ou Raça que se autodeclara.
( ) Branca
( ) Amarela
( ) Parda
( ) Negra
( ) Indígena
( ) Não declarada

38) Você já sofreu algum tipo de discriminação? ( ) Racial （）Social （）Econômica ( ) Gênero ( ) Biotipo Físico

39) Qual o meio de transporte que você geralmente utiliza no dia a dia?
( ) Bicicleta
( ) Moto
( ) Transporte público coletivo
( ) Táxi
( ) Carro

( ) Outros

40) De modo geral, como você qualifica a ação dos Governos nos últimos 12 meses:
( ) Ótimo
( ) Bom
( ) Regular
( ) Péssimo

41) Você confia na administração pública do seu município? （） Sim （） Não

42) Você votou nas últimas eleições?

( ) Sim

( ) Não

43) Você discute política? ( ) Sim

( ) Não

44) Com relação à segurança, como você se sente na sua casa? ( ) Inseguro （） Pouco seguro

( ) Seguro ( ) Muito seguro

45) Você sente-se infeliz ou deprimido (a)? ( ) Sempre ( ) Às vezes

( ) Raramente ( ) Nunca

46) Cite três coisas que te deixam feliz: 